\title{
Desastre natural associado a evento de chuva intensa no município de Caldas Brandão, Paraíba
}

\author{
Natural disaster associated with the event of intense rainfall in the municipality of Caldas \\ Brandão, Paraíba
}

CAVALCANTE ${ }^{1}$, G. P.; TEMOTEO ${ }^{1}$, K. K. S.

cavalcantegp.geo@gmail.com;

\begin{abstract}
Resumo
O presente artigo tem como objetivo analisar o regime das chuvas e a deflagração de desastres naturais no município de Caldas Brandão, Agreste da Paraíba. Para o cumprimento deste objetivo, foram executadas duas etapas principais, que correspondem a análise da variação da precipitação e o levantamento dos desastres naturais. Os dados de precipitação foram disponibilizados pela Agência Executiva de Gestão das Águas do Estado da Paraíba - AESA. Já as informações referentes aos desastres naturais foram adquiridas no site do Sistema Integrado de Informações sobre Desastres - S2ID e nos formulários de Avaliação de Danos - AVADAN do Sistema Nacional de Defesa Civil - SINDEC. Foram registrados 34 eventos intensos e extremos de chuva. O evento mais significativo ocorreu no dia 01/02/2004, com registro de 126,6 $\mathrm{mm}$, porém, o único desastre hidrometeorológico registrado pela Defesa Civil está associado ao episódio ocorrido entre os dias 19 e $22 / 01 / 2004$, que acumulou $134,8 \mathrm{~mm}$, sendo o evento do dia 21/01/2004 o mais significativo, com registro de 85,8 $\mathrm{mm}$, o que representa $61,7 \%$ do acumulado do mês.
\end{abstract}

Palavras-chave: Chuvas Intensas e Extremas, Desastres Naturais, Enxurradas e Inundações.

\begin{abstract}
The present article aims to analyze the rainfall regime and the outbreak of natural disasters in the municipality of Caldas Brandão, Agreste of Paraíba. In order to achieve this objective, two main steps were carried out, which correspond to the analysis of precipitation variation and the survey of natural disasters. The precipitation data were made available by the Executive Agency for the Management of Waters of the State of Paraíba - AESA. Information on natural disasters was also obtained through the website of the Integrated Disaster Information System (S2ID) and in the Damage Assessment forms (AVADAN) of the National Civil Defense System (SINDEC). There were 34 intense and extreme rain events. The most significant event occurred on $01 / 02 / 2004$, with a record of $126.6 \mathrm{~mm}$, but the only hydrometeorological disaster recorded by Civil Defense is associated to the episode occurred between 19 and $22 / 01 / 2004$, which accumulated $134,8 \mathrm{~mm}$, the event of the 21/01/2004 being the most significant, with a record of $85.8 \mathrm{~mm}$, which represents $61.7 \%$ of the accumulated of the month.
\end{abstract}

Keywords: Heavy and Extreme Rains, Natural Disasters, Rust and Flood.

\section{INTRODUÇÃO}

Os eventos pluviométricos extremos são fenômenos excepcionais da atmosfera que, quando ocorrem em espaços urbanos, podem ser estudados de forma dinâmica (MONTEIRO, 1976). Já os desastres naturais, que podem ser deflagrados por esses eventos, ocorrem como reações do sistema ambiental físico às forças de distúrbio aplicadas pela natureza, podendo causar danos humanos, ambientais, econômicos e ao setor público (TOMINAGA, 2009; BRASIL, 2012).

Com o rápido crescimento urbano no Brasil a partir de 1970, os desastres naturais passaram a ser cada vez mais frequentes, principalmente, em decorrência da fragilidade ambiental das áreas 
ocupadas (ZAMPARONI, 2014; SILVA e ARAÚJO, 2017). O Escritório das Nações Unidas para a Redução do Risco de Desastres classifica os desastres naturais como:

(...) uma grave perturbação do funcionamento de uma comunidade ou de uma sociedade envolvendo perdas humanas, materiais, econômicas ou ambientais de grande extensão, cujos impactos excedem a capacidade da comunidade ou da sociedade afetada de arcar com seus próprios recursos. (TOMINAGA, et. al., 2009, p. 13).

Já a Defesa Civil utiliza critérios parecidos para definir desastre natural, acrescentando a vulnerabilidade como fator determinante:

\begin{abstract}
“(...) resultado de eventos adversos, naturais ou provocados pelo homem, sobre um ecossistema (vulnerável), causando danos humanos, materiais e/ou ambientais e consequentes prejuízos econômicos e sociais. A intensidade de um desastre depende da interação entre a magnitude do evento adverso e o grau de vulnerabilidade do sistema receptor afetado" (CASTRO, 1998 apud. TOMINAGA, 2009).
\end{abstract}

Os tipos e as características dos desastres naturais que ocorrem no Brasil estão inseridos na Classificação e Codificação Brasileira de Desastres Naturais - COBRADE, vigente na Instrução Normativa $N^{\circ}$ 01, de 24 de agosto de 2012 do Ministério da Integração Nacional. No tocante às origens, os desastres podem ser de natureza geológica, hidrológica, meteorológica, climática e biológica, sendo os hidrológicos e hidrometeorológicos provocados pelos eventos intensos e extremos de chuva, podendo, assim, ser agrupados em uma mesma categoria: os hidrometeorológicos. (BRASIL, 2012; TEMOTEO, 2016).

Segundo Olímpio (2013), os eventos pluviométricos intensos e extremos podem desencadear desastres naturais que:

(...) ocorrem pela ação conjunta de mais de um evento natural ou decorrem da manifestação de um evento que promova a ocorrência de outros. Tal situação é observada, por exemplo, durante os episódios pluviais intensos, as quais podem produzir enchentes, alagamentos, enxurradas, deslizamentos, corridas de lama, vendavais, desabamentos, prejuízos à saúde pública, dentre outros (OLIMPIO, 2013, p. 45-46).

Assim, levanta-se a hipótese de que tais eventos podem causar impactos nas cidades do Agreste Paraibano como Caldas Brandão, pois, além das condições climáticas características de um espaço natural de transição, muitas cidades estão localizadas às margens de rios e/ou possuem relevo ondulado e acidentado, característico da região da Borborema. Além dos eventos pluviométricos intensos e extremos provocarem impactos intra-urbanos, principalmente em cidades que possuem ocupações não planejadas em áreas de terreno acidentado, há também os riscos de inundações em regiões rurais, principalmente nas margens dos rios, regiões com ocupação intensa devido às atividades agropecuárias.

Segundo Moura et. al. (2017), as cidades do semiárido, nas quais os desastres naturais do tipo estiagem/seca são mais frequentes, as chuvas também podem gerar impactos: 
Para as cidades do interior da região, [...] os eventos de chuvas intensas e extremas possuem periodicidade esporádica. Por sua vez, estes podem gerar desastres hidrológicos com intensidades comparadas com os desastres de estiagem/seca (OLÍMPIO, 2013; ROCHA, 2015). (MOURA et. al, 2017).

O município de Caldas Brandão (Figura 1) se localiza na porção leste do Agreste Paraibano (faixa da Depressão Sublitorânea). A população estimada para o ano de 2017 é de 6.025 habitantes (IBGE, 2017), distribuída em um espaço territorial de 55,8 $\mathrm{km}^{2}$. O objetivo deste estudo é, portanto, analisar o regime pluviométrico de Caldas Brandão e associá-lo a possíveis desastres hidrometeorológicos.
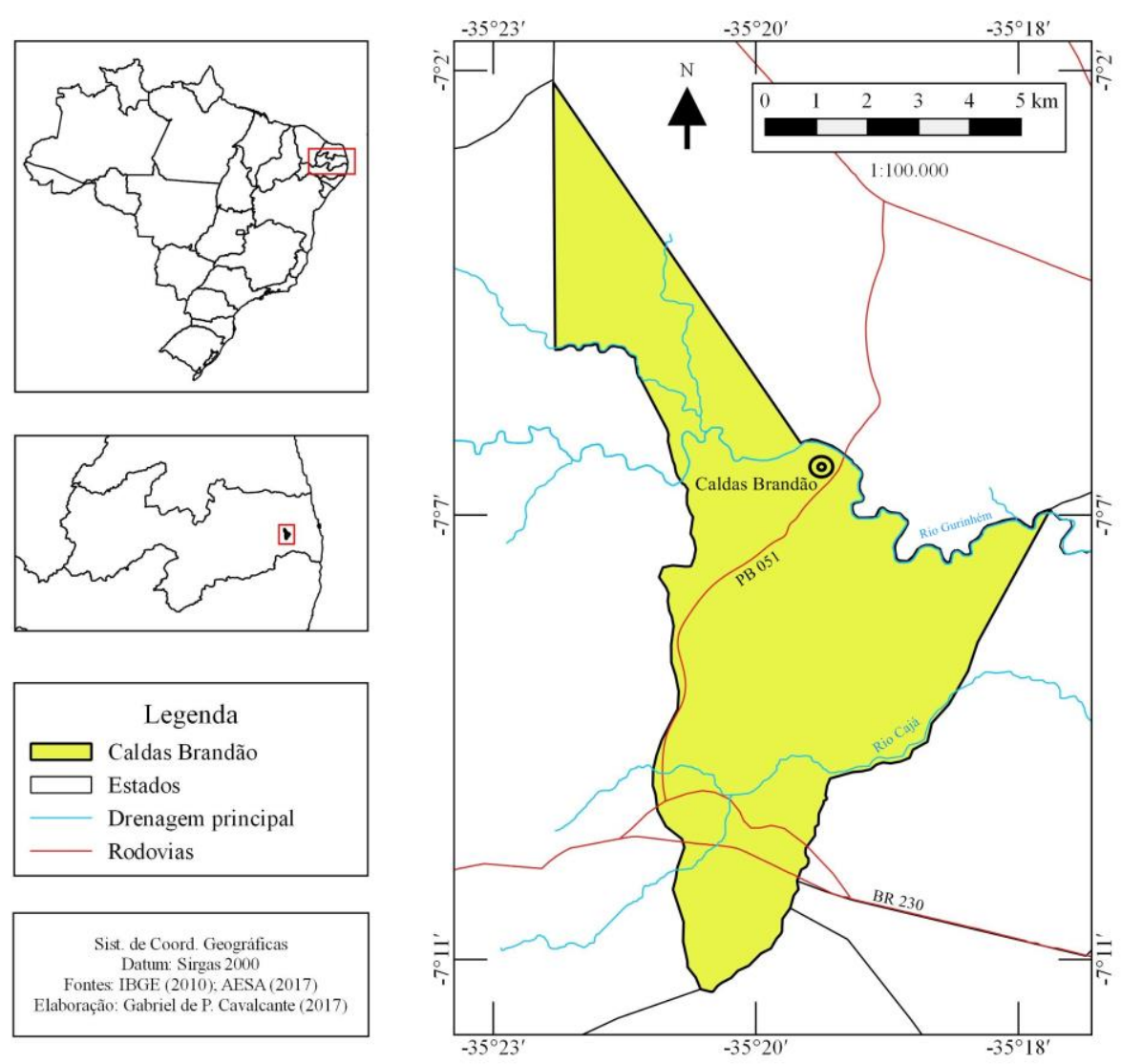

Figura 1 - Localização do município de Caldas Brandão-PB.

A escolha desse município se deu em virtude de dois fatores:

1) Há dois espaços urbanos no município (a sede municipal e um distrito), ambos localizados às margens de rios da Bacia do Paraíba (Rio Gurinhém e Rio Cajá, respectivamente) e cortados por importantes vias asfálticas (PB 051 e BR 230, de forma respectiva);

2) Por ser o município dotado de um espaço territorial pequeno, a zona rural é relevantemente povoada, o que faz aumentar a pressão antrópica sobre os sistemas ambientais, potencializando impactos durante e após eventos extremos de chuva, a exemplo de rompimento de barramentos e passagens molhadas; o setor agrícola também recebe impactos, já que a ocupação nas várzeas dos rios e riachos é comum. 


\section{METODOLOGIA}

Para o estudo das chuvas e da deflagração de desastres naturais no município de Caldas Brandão foram executadas duas etapas, que corresponderam ao tratamento dos dados referentes ao atributo climático (precipitação) e das informações sobre os desastres hidrometeorológicos.

\section{1 - Da precipitação}

Realizou-se um estudo exploratório da série diária de precipitação de 1994 a 2016. Assim, foram executados os seguintes procedimentos:

- Obtenção dos dados históricos no banco de dados da Agência Executiva de Gestão das Águas do Estado da Paraíba - AESA;

- Confecção de tabelas no ambiente do Microsoft Excel 2010 (Microsoft Corporation), no formato de planilhas eletrônicas, para a sistematização da base de dados e verificação de falhas da série;

- Cálculo do desvio total e percentual de precipitação para as estações do ano e, em seguida, para os anos, a fim de que sejam classificados os períodos secos, tendentes a secos, habituais, tendentes a chuvosos e chuvosos;

- Detecção dos eventos pluviais mais significativos (intensos e extremos) e observação da dinâmica climática - sobretudo a atuação dos sistemas atmosféricos - dos eventos que possuem desastres associados.

\subsection{1 - Da eleição dos períodos quanto ao padrão de precipitação}

Os períodos secos, tendente a seco, habitual, tendente a chuvoso e chuvoso foram classificados de acordo com os parâmetros de Sant'Anna Neto (1990), que utiliza o coeficiente de variação como critério de escolha dos períodos padrão, como destacam Moura e Pereira (2015).

O parâmetro obedece a categorias de desvios percentuais:

- período chuvoso: registros com desvios positivos superiores a 25\% da média histórica;

- período tendente a chuvoso: registros com desvios positivos entre $12,5 \%$ e $25 \%$;

- período habitual: registros com desvios variáveis de $-12,5 \%$ a +12,5\%;

- período tendente a seco: registros com desvios negativos entre $-12,5 \%$ e $-25 \%$;

- e período seco: registros com desvios negativos inferiores a $-25 \%$. 


\subsection{2 - Dos eventos pluviais intensos e extremos}

De acordo com Gonçalves (2003), Zanella, Sales e Abreu (2009), Cavalcanti (2009), Zanella (2014), Silva (2014) e Temoteo (2016) são considerados eventos intensos aqueles iguais os superiores a $60,0 \mathrm{~mm} / \mathrm{dia}$ e eventos extremos aqueles iguais ou superiores a 100,0 mm/dia. Embora esses estudos tenham sido aplicados em cidades diferentes (variações diversas entre os sítios urbanos, as formas de ocupação, entre outras características), a compreensão das respostas dos sistemas ambientais ocorre por meio do levantamento dos impactos gerados pelos eventos, e não apenas pela magnitude dos mesmos. Ou seja, um evento classificado como intenso pode gerar impactos mais graves do que um evento extremo, dependendo das condições de instalação da cidade e da capacidade de resposta do ambiente.

\section{2 - Dos desastres naturais}

Para identificação dos impactos causados pelos eventos pluviométricos extremos e os desastres naturais resultantes foram utilizadas as portarias de reconhecimento de Situação de Emergência - SE e as portarias de Estado de Calamidade Pública - ECP, fornecidas pelo Banco de Dados de Registro de Desastres, gerenciado pela Secretaria Nacional de Defesa Civil - SEDEC disponíveis na página do site do Sistema Integrado de Informações sobre Desastres - S2ID. Também serão utilizados os formulários de Avaliação de Danos - AVADAN do Sistema Nacional de Defesa Civil - SINDEC, com o propósito de mensurar os danos ambientais, humanos, materiais e os prejuízos sociais e econômicos gerados em decorrência dos desastres naturais.

\section{RESULTADOS E DISCUSSÃO}

\section{1 - Análise da precipitação média mensal e dos "anos-padrão"}

Entre os anos de 1994 e 2016, a média histórica anual de precipitação para o município de Caldas Brandão foi de 893,3 mm. A Figura 2 mostra a distribuição anual da precipitação. Os anos mais chuvosos foram $2011(1517,5 \mathrm{~mm}), 2000(1384,5 \mathrm{~mm})$ e 2009 (1271,2); já os anos que registraram os menores quantitativos de chuva foram 2006 (587,4 mm), $2010(557,7)$ e 1998 $(538,1)$. A variação anual das chuvas revela a dinamicidade climática da região, principalmente pelo fato da mesma se situar em um espaço de transição - o Agreste. 


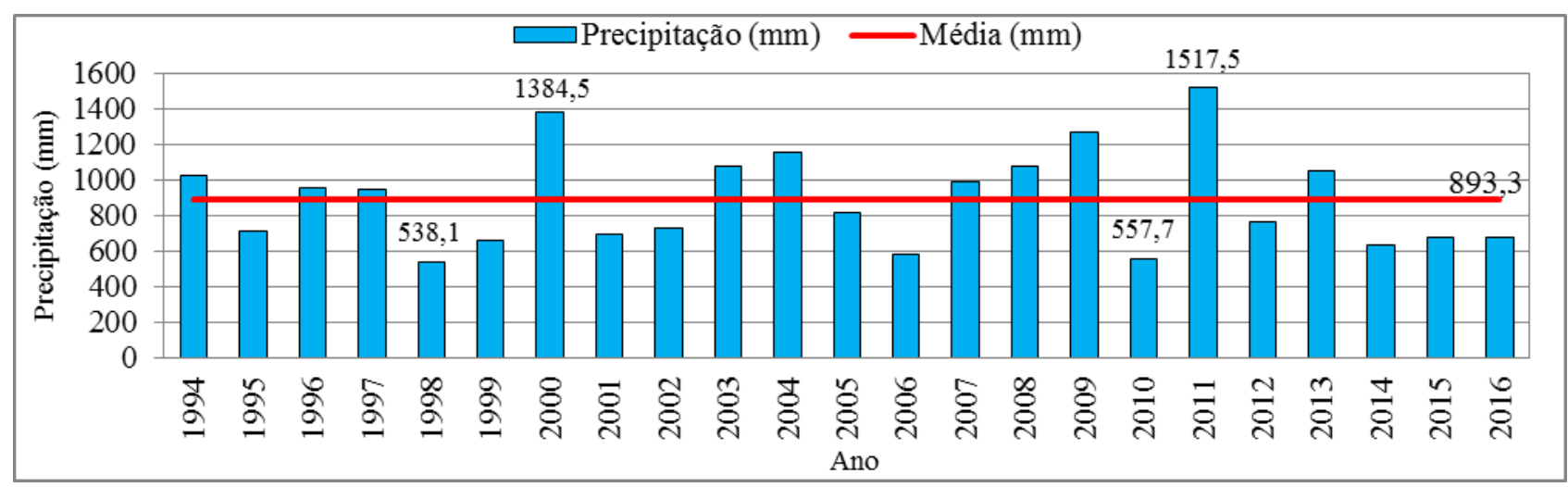

Figura 2 - Totais anuais de precipitação no município de Caldas Brandão-PB. Fonte: AESA (2017). Elaboração: Gabriel de Paiva Cavalcante (2017).

Na classificação mensal, têm-se três períodos, compostos por quatro meses cada, a saber: pré-estação chuvosa (janeiro a abril), estação chuvosa (maio a agosto) e estação seca (setembro a dezembro). A Figura 3 mostra a precipitação média mensal.

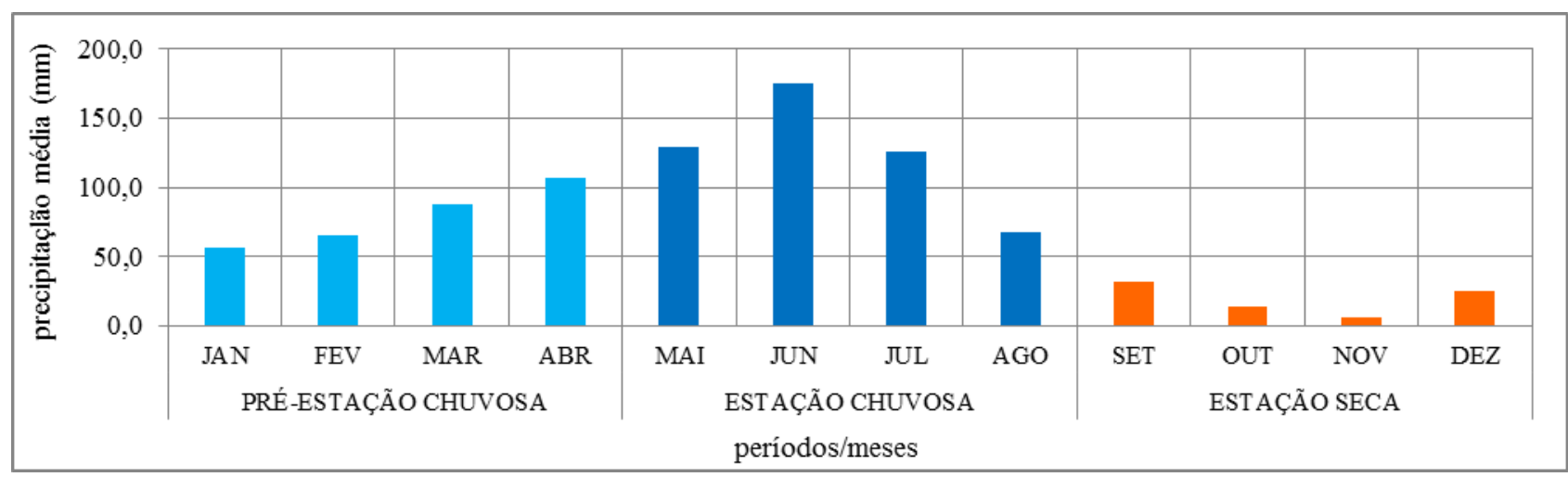

Figura 3 - Média histórica mensal de chuvas em Caldas Brandão-PB. Fonte: AESA (2017). Elaboração: Gabriel de Paiva Cavalcante (2017).

A distribuição das chuvas entre os meses e períodos sazonais se concentra principalmente na estação chuvosa $(55,7 \%)$, sendo junho o mês mais chuvoso: média de $174,8 \mathrm{~mm}$. A pré-estação chuvosa registra $35,6 \%$ das chuvas no município, ocorrendo de forma crescente na comparação fenômeno-tempo. Por fim, o período seco registrou apenas 8,7\% das chuvas.

O Quadro 1 mostra a variação sazonal e anual da precipitação. A estação chuvosa do ano 2011 se destaca como o período que registrou os maiores desvios (absoluto e relativo) da série: $544,8 \mathrm{~mm}$ e $+109,5 \%$, de forma respectiva; já os anos com os maiores desvios positivos absolutos e relativos são 2011 (+624,2 mm e +69,88\%, respectivamente) e 2000 (+491,2 mm e +54,99\%, respectivamente). 


\begin{tabular}{|c|c|c|c|c|c|c|}
\hline Ano & Período & Precipitação da estação & Desvio Total & Desvio percentual da estação & Precipitação do ano & Desvio total $(\mathrm{mm})$ \\
\hline \multirow{3}{*}{1994} & PEC & 315,0 & \begin{tabular}{|c|}
$-3,0$ \\
\end{tabular} & $-0,9$ & \multirow{3}{*}{1030,9} & \multirow{3}{*}{15,4} \\
\hline & $\mathrm{EC}$ & 605,5 & 107,9 & 21,7 & & \\
\hline & ES & 110,4 & 32,8 & 42,3 & & \\
\hline \multirow{3}{*}{1995} & PEC & 235,3 & $-82,7$ & $-26,0$ & \multirow{3}{*}{715,8} & \multirow{3}{*}{$-19,9$} \\
\hline & $\mathrm{EC}$ & 450,1 & $-47,5$ & $-9,5$ & & \\
\hline & ES & 30,4 & $-47,2$ & $-60,8$ & & \\
\hline \multirow{3}{*}{1996} & PEC & 412,0 & 94,0 & 29,6 & & \\
\hline & EC & 416,9 & $-80,7$ & $-16,2$ & 959,6 & 7,4 \\
\hline & ES & 130,7 & 53,1 & 68,4 & & \\
\hline & PEC & 470,1 & 152,1 & 47,8 & & \\
\hline 1997 & EC & 391,7 & $-105,9$ & $-21,3$ & 944,9 & 5,8 \\
\hline & ES & 83,1 & 5,5 & 7,1 & & \\
\hline & PEC & 135,4 & $-182,6$ & $-57,4$ & & \\
\hline 1998 & $\mathrm{EC}$ & 385,7 & $-111,9$ & $-22,5$ & 538,1 & $-39,8$ \\
\hline & ES & 17,0 & $-60,6$ & $-78,1$ & & \\
\hline & PEC & 229,7 & $-88,3$ & $-27,8$ & & \\
\hline 1999 & EC & 352,6 & $-145,0$ & $-29,1$ & 660,1 & $-26,1$ \\
\hline & ES & 77,8 & 0,2 & 0,3 & & \\
\hline & PEC & 329,0 & 11,0 & 3,5 & & \\
\hline 2000 & EC & 804,5 & 306,9 & 61,7 & 1384,5 & 55,0 \\
\hline & ES & 251,0 & 173,4 & 223,5 & & \\
\hline & PEC & 294,7 & $-23,3$ & $-7,3$ & & \\
\hline 2001 & $\mathrm{EC}$ & 328,7 & $-168,9$ & $-33,9$ & 693,5 & $-22,4$ \\
\hline & ES & 70,1 & $-7,5$ & $-9,7$ & & \\
\hline & PEC & 218,2 & $-99,8$ & $-31,4$ & & \\
\hline 2002 & EC & 472,2 & $-25,4$ & $-5,1$ & 729,5 & $-18,3$ \\
\hline & ES & 39,1 & $-38,5$ & $-49,6$ & & \\
\hline & PEC & 571,8 & 253,8 & 79,8 & & \\
\hline 2003 & EC & 416,1 & $-81,5$ & $-16,4$ & 1078,1 & 20,7 \\
\hline & ES & 90,2 & 12,6 & 16,2 & & \\
\hline & PEC & 503,7 & 185,7 & 58,4 & & \\
\hline 2004 & EC & 612,6 & 115,0 & 23,1 & 1160,1 & 29,9 \\
\hline & ES & 43,8 & $-33,8$ & $-43,6$ & & \\
\hline & PEC & 138,1 & $-179,9$ & $-56,6$ & & \\
\hline 2005 & EC & 639,5 & 141,9 & 28,5 & 820,5 & $-8,1$ \\
\hline & ES & 42,9 & $-34,7$ & $-44,7$ & & \\
\hline & PEC & 225,1 & $\begin{array}{l}-92,9 \\
\end{array}$ & $-29,2$ & & \\
\hline 2006 & EC & 310,4 & $-187,2$ & $-37,6$ & 587,4 & $-34,2$ \\
\hline & ES & 51,9 & $-25,7$ & $-33,1$ & & \\
\hline & PEC & 366,1 & 48,1 & 15,1 & & \\
\hline 2007 & EC & 495,8 & $-1,8$ & $-0,4$ & 987,8 & 10,6 \\
\hline & ES & 125,9 & 48,3 & 62,2 & & \\
\hline & PEC & 446,7 & 128,7 & 40,5 & & \\
\hline 2008 & EC & 583,1 & 85,5 & 17,2 & 1081,7 & 21,1 \\
\hline & ES & 51,9 & $-25,7$ & $-33,1$ & & \\
\hline & PEC & 499,4 & 181,4 & 57,0 & & \\
\hline 2009 & EC & 735,9 & 238,3 & 47,9 & 1271,2 & 42,3 \\
\hline & ES & 35,9 & $-41,7$ & $-53,7$ & & \\
\hline & PEC & 234,0 & $-84,0$ & $-26,4$ & & \\
\hline 2010 & EC & 283,0 & $-214,6$ & $-43,1$ & 557,7 & $-37,6$ \\
\hline & ES & 40,7 & $-36,9$ & $-47,6$ & & \\
\hline & PEC & 414,8 & 96,8 & 30,4 & & \\
\hline 2011 & EC & 1042,4 & 544,8 & 109,5 & 1517,5 & 66,9 \\
\hline & ES & 60,3 & $-17,3$ & $-22,3$ & & \\
\hline & PEC & 216,9 & $-101,1$ & $-31,8$ & & \\
\hline 2012 & EC & 524,7 & 27,1 & 5,4 & 770,0 & $-13,8$ \\
\hline & ES & 28,4 & $-49,2$ & $-63,4$ & & \\
\hline & PEC & 302,1 & $-15,9$ & $-5,0$ & & \\
\hline 2013 & EC & 600,9 & 103,3 & 20,8 & 1056,3 & 18,2 \\
\hline & ES & 153,3 & 75,7 & 97,6 & & \\
\hline & PEC & 211,1 & $-106,9$ & $-33,6$ & & \\
\hline 2014 & EC & 346,7 & $-150,9$ & $-30,3$ & 640,1 & $-28,3$ \\
\hline & ES & 82,3 & 4,7 & 6,1 & & \\
\hline & PEC & 225,0 & $-93,0$ & $-29,2$ & & \\
\hline 2015 & $\mathrm{EC}$ & 365,2 & $-132,4$ & $-26,6$ & 670,7 & $-24,2$ \\
\hline & $\mathrm{ES}$ & 80,5 & 2,9 & 3,7 & & \\
\hline & PEC & 314,3 & $-3,7$ & $-1,2$ & & \\
\hline 2016 & $\mathrm{EC}$ & 281,1 & $-216,5$ & $-43,5$ & 683,3 & $-23,5$ \\
\hline & ES & 87,9 & 10,3 & 13,3 & & \\
\hline & & & & & LEGENDA & \\
\hline & & & & \begin{tabular}{|l|} 
Categoria \\
\end{tabular} & & svio \\
\hline & PEC & : Pré-Estação Chuvo & & Ano Chuvoso & mais de $25 \%$ & \\
\hline & & C: Estação Chuvosa & & Tendente a chuvoso & de $12,5 \%$ A $25 \%$ & \\
\hline & & ES: Estação Seca & & Habitual & de $-12,5 \%$ A $12,5 \%$ & \\
\hline & & & & \begin{tabular}{|l|} 
Tendente a seco \\
\end{tabular} & de $-12,5 \mathrm{~A}-25 \%$ & \\
\hline & & & & Seco & menos de $-25 \%$ & \\
\hline
\end{tabular}

Quadro 1 - Variação interestacional e interanual de precipitação no município de Caldas Brandão-PB. Fonte: AESA (2017). Elaboração: Gabriel de Paiva Cavalcante (2017). 
Os maiores desvios negativos (absolutos e relativos) foram registrados nos anos de 1998 ($355,2 \mathrm{~mm}$ e $-39,76 \%$, respectivamente) e 2010 (-335,6 $\mathrm{mm} \mathrm{e}-37,57 \%$, respectivamente). Nas estações desses dois anos, destacam-se os desvios da estação seca de 1998 (-60,6 mm de desvio absoluto e $-78,1 \%$ de desvio relativo) e do enquadramento das três estações de 2010 na categoria "Muito Seco", com registro de $-26,4 \%$ na pré-estação chuvosa, $-43,1 \%$ na estação chuvosa e $-47,6 \%$ na estação seca.

\subsection{Ritmo diário das chuvas}

Para a representação dos três períodos significativos dos "anos-padrão", foram eleitos os anos 1998 (ano Seco), 1997 (ano Habitual) e 2011 (ano Chuvoso). O Quadro 2 mostra a quantidade de dias com chuva e de dias sem chuvas nestes anos. Considerou-se dia com chuva aquele que registrou mais de $0,5 \mathrm{~mm}$ de chuva.

Quadro 2 - Quantidade e percentual de dias com chuva e dias sem chuva em "anos-padrão".

\begin{tabular}{|c|c|c|c|c|}
\hline Ano & Dias com chuva & Percentual & Dias sem chuva & Percentual \\
\hline 1998 (ano Seco) & 42 & 11,5 & 323 & 88,5 \\
\hline 1997 (ano Habitual) & 58 & 15,9 & 307 & 84,1 \\
\hline 2011 (ano Chuvoso) & 131 & 35,9 & 234 & 64,1 \\
\hline
\end{tabular}

Fonte: AESA; Elaboração: Gabriel de Paiva Cavalcante, 2017.

Observa-se que o ano Chuvoso apresenta a maior quantidade de dias com chuva, enquanto que o ano Seco, os menores quantitativos. Em 1997, mesmo com registro habitual de chuva, os dados foram próximos aos do ano seco: foram 16 dias a mais com chuva acima de 0,5 mm. O número elevado de dias com chuva em 2011 ocorre devido ao destaque desse período no que diz respeito aos desvios positivos de precipitação, a exemplo da Estação Chuvosa, quando choveu 109,5\% acima da normal histórica. As Figuras 4, 5 e 6 mostram o ritmo diário das chuvas nestes anos representativos. Este critério foi utilizado por Moura e Pereira (2015).

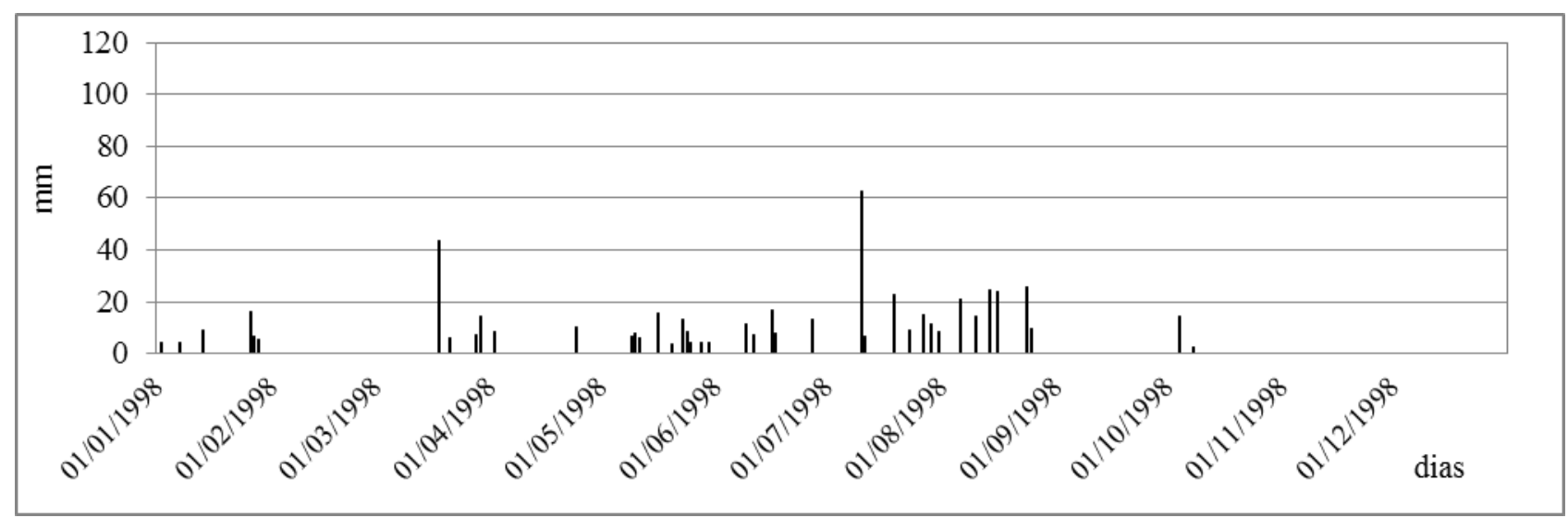

Figura 4 - Ritmo diário das chuvas em 1998, "ano-padrão" Seco. Fonte: AESA (2017). Elaboração: Gabriel de Paiva Cavalcante (2017). 


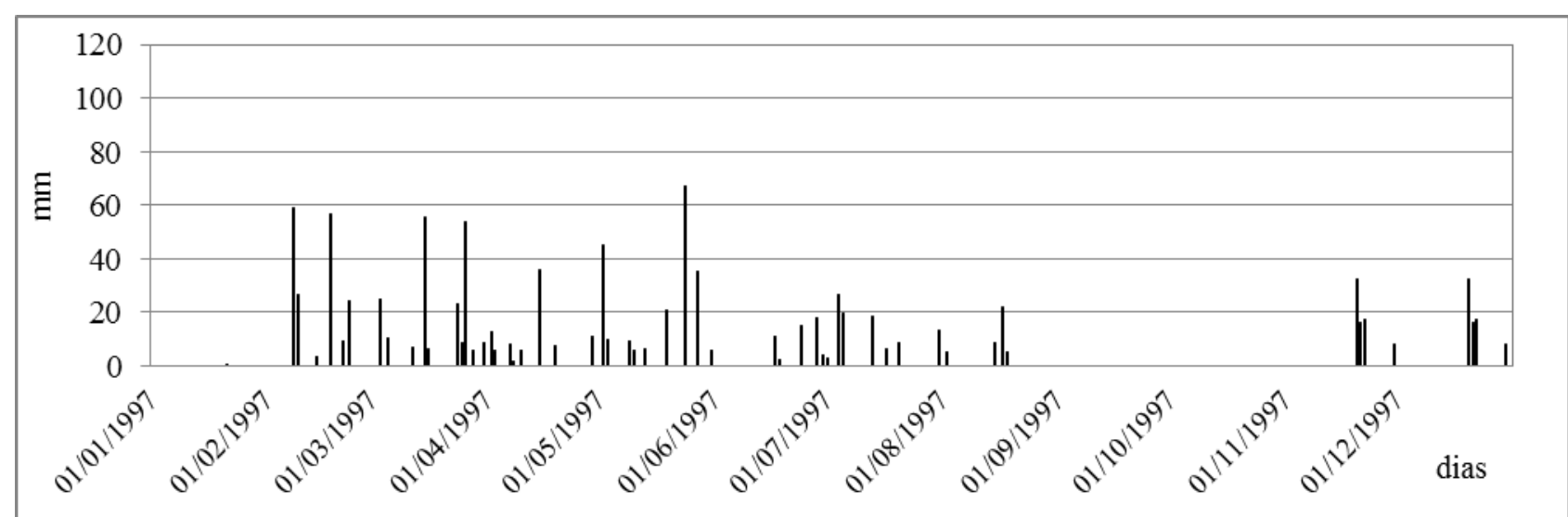

Figura 5 - Ritmo diário das chuvas em 1997, “ano-padrão" Habitual. Fonte: AESA (2017). Elaboração: Gabriel de Paiva Cavalcante (2017).

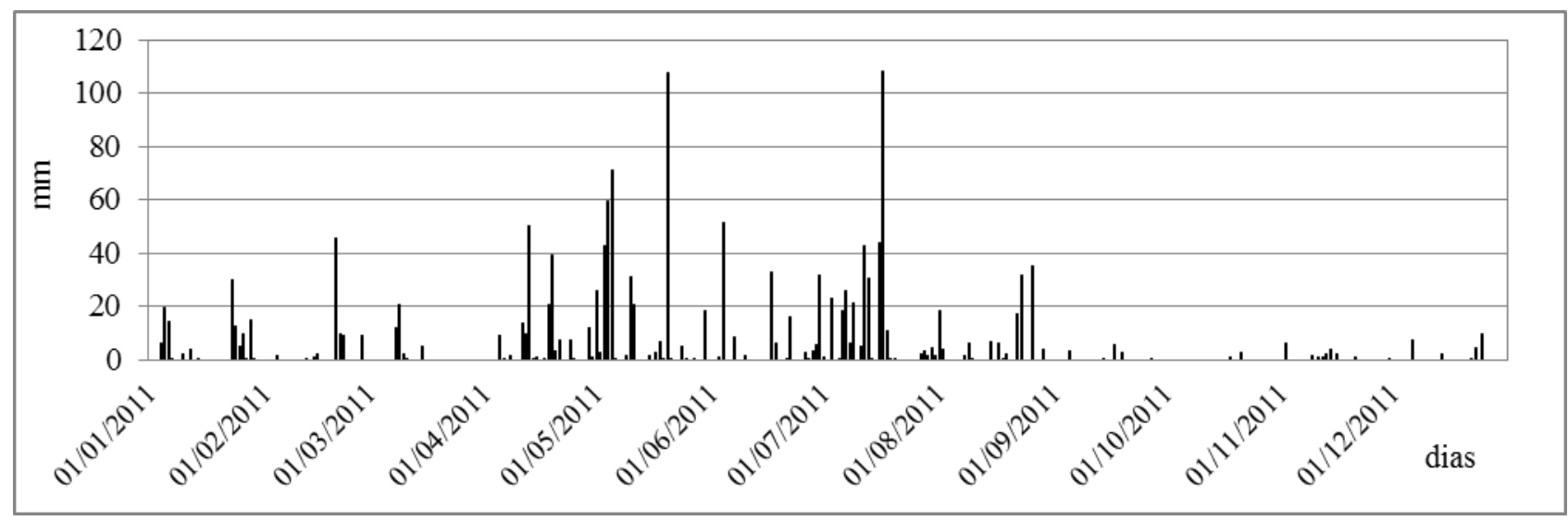

Figura 6 - Ritmo diário das chuvas em 1998, "ano-padrão" Chuvoso. Fonte: AESA (2017). Elaboração: Gabriel de Paiva Cavalcante (2017).

Em 1998, ano Seco, houve apenas um dia com precipitação intensa: 10/07/1998, com registro de $62,4 \mathrm{~mm}$. O segundo dia com maior registro de chuva foi 18/03/1998, com 43,3 mm. Todos os demais registros diários não ultrapassaram os $26,0 \mathrm{~mm}$. Neste ano, as chuvas se concentraram entre março e agosto. O ano de 1997 (Habitual) apresenta equilíbrio e regularidade quanto aos eventos de chuva: há 6 registros diários entre 45,0 mm e 68,0 mm, sendo 24/05/1997 o dia mais chuvoso do ano, com registro de $67,4 \mathrm{~mm}$. As chuvas se concentraram, principalmente, entre fevereiro e maio. Já em 2011, ano chuvoso, foram registrados dois eventos extremos: 20/05/2011 com registro de 107,4 mm e 17/07/2011 com 107,9 mm. Há ainda 8 eventos acima dos 40,0 mm. Ocorreram dias com chuva em todos os meses, mas destaca-se o período entre abril e julho, no qual ocorrem os eventos extremos.

\section{2 - Eventos de chuva intensa e extrema}

Foram registrados 34 eventos pluviométricos acima de $60,0 \mathrm{~mm} /$ dia, sendo três enquadrados na categoria de eventos extremos (chuva acima dos 100,0 mm/dia). O ano com maior número de ocorrências foi 2000 (ano chuvoso, quatro ocorrências), seguido de 1994 (ano tendente a chuvoso), 
2004 (ano chuvoso) e 2011 (ano chuvoso), com três ocorrências cada, já os anos 1995, 2002 e 2015 (tendentes a secos) e 2006 e 2014 (anos secos) não registraram eventos. Nota-se a relação direta entre as categorias pluviométricas dos anos e os registros de eventos. A Figura 7 mostra a ocorrência anual de eventos intensos e extremos.

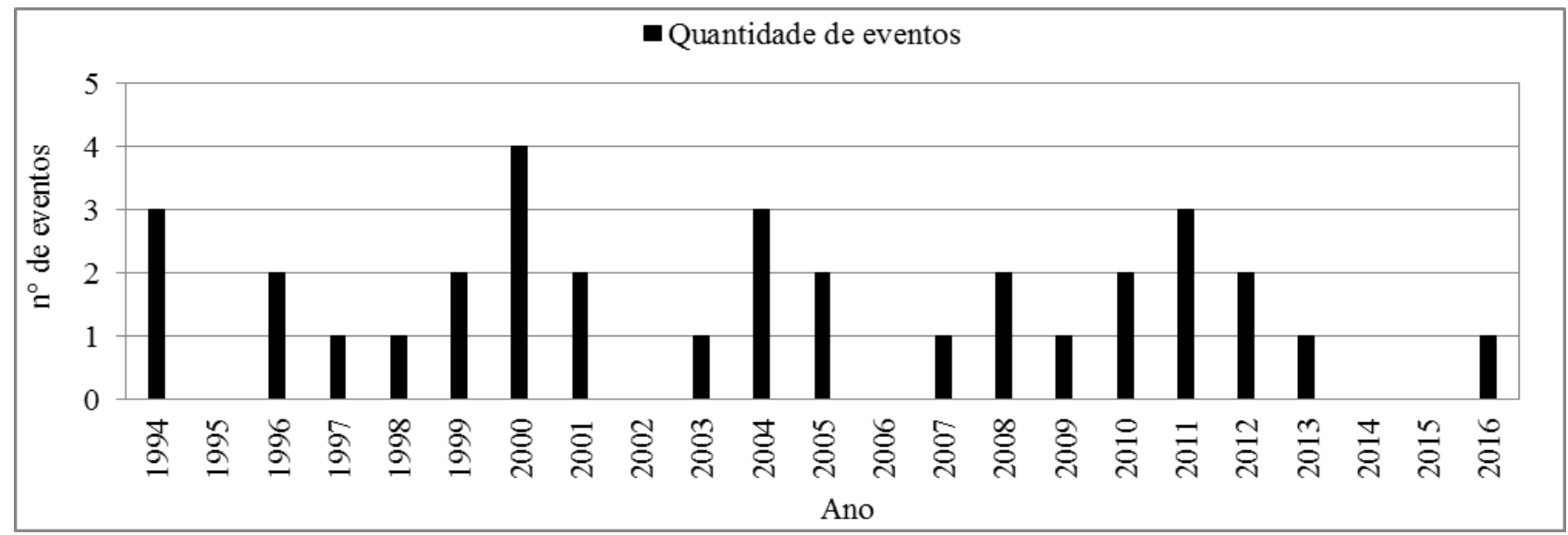

Figura 7 - Ocorrência anual de eventos intensos e extremos no município de Caldas Brandão-PB. Fonte: AESA (2017). Elaboração: Gabriel de Paiva Cavalcante (2017).

Os três eventos extremos ocorreram nos anos 2004 (um evento ocorrido no dia 01/04/2004 que registrou um total de 126,6 mm) e 2011 (dois eventos um no dia 20/05/2011 que registrou um total de 107,4 mm; e um segundo que ocorreu no dia 17/07/2011 e registrou um total de 107,9 mm).

O evento analisado neste trabalho é o do dia 21/01/2004, associado a um desastre natural hidrometeorológicos (enxurrada ou inundação brusca), de acordo com um AVADAN da Defesa Civil (BRASIL, 2004).

\subsection{1 - Análise do evento intenso do dia 21/01/2004}

O mês de janeiro de 2004 (Figura 8) registrou 139,0 mm de chuva (82,3 mm acima da média histórica, que é de 56,7 mm). O evento do dia 21/01/2004, enquadrado na categoria de evento intenso, registrou $85,8 \mathrm{~mm}$, o que representa $61,7 \%$ do acumulado do mês. Tal evento foi precedido por um acumulado de 29,0 mm no dia anterior. Somando as chuvas dos quatro dias - 19 a 22/01/2004, tem-se um episódio de 134,8 mm. Tal episódio está associado ao Decreto de Situação de Emergência que gerou um AVADAN no dia 28/01/2004.

Além desse episódio no mês de janeiro, merece destaque um evento extremo ocorrido no dia 01/02/2004, que registrou o maior acumulado diário da série investigada: 126,6 mm e, provavelmente, agravou os impactos gerados entre 19 e 22/01/2004, porém não há registros que comprovem tal agravo. 
De acordo com o Boletim Climanálise (2004), as chuvas registradas durante o episódio ocorreram devido ao deslocamento de frentes frias para o norte, à atuação da Zona de Convergência Intertropical (ZCIT) e à presença de Vórtices Ciclônicos em Altos Níveis (VCAN) no mês de janeiro; já em fevereiro, foram consequências da combinação de um VCAN e da ZCIT. Em janeiro, as chuvas acima da média ocorreram de forma generalizada na região, diminuindo na segunda quinzena de fevereiro que, embora os maiores quantitativos de chuva tenham sido registrados entre o Maranhão e o Ceará, outras áreas também se destacaram, como o Agreste e a Zona da Mata da Paraíba. A Figura 9 mostra a imagem de satélite do dia 21/01/2004.

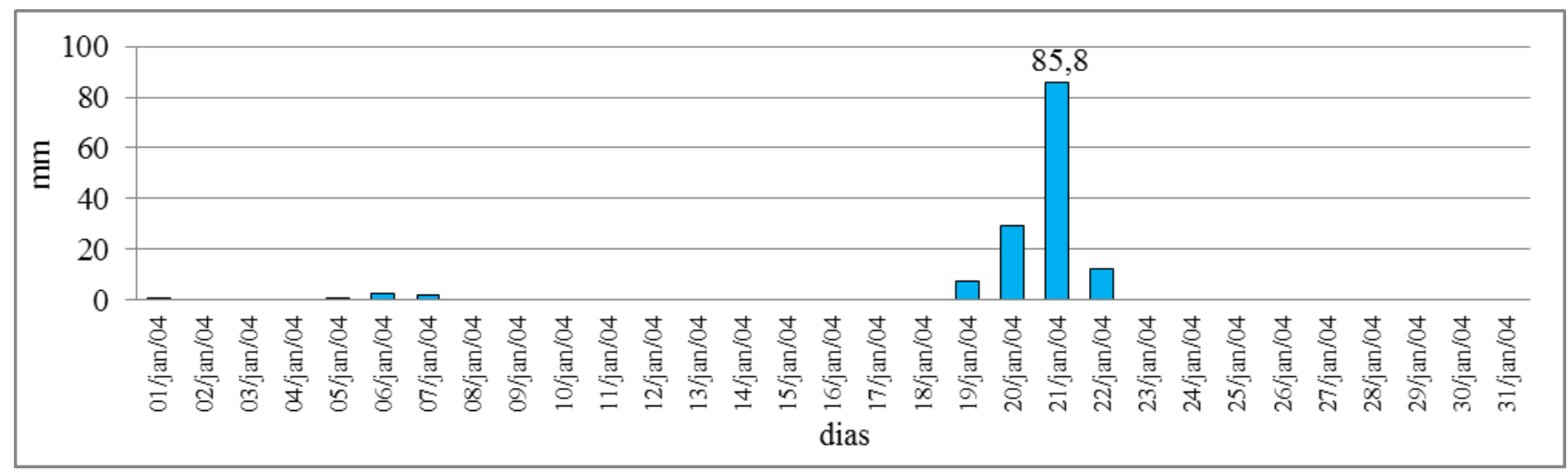

Figura 8 - Precipitação diária do mês de janeiro no município de Caldas Brandão-PB. Fonte: AESA (2017). Elaboração: Gabriel de Paiva Cavalcante (2017).

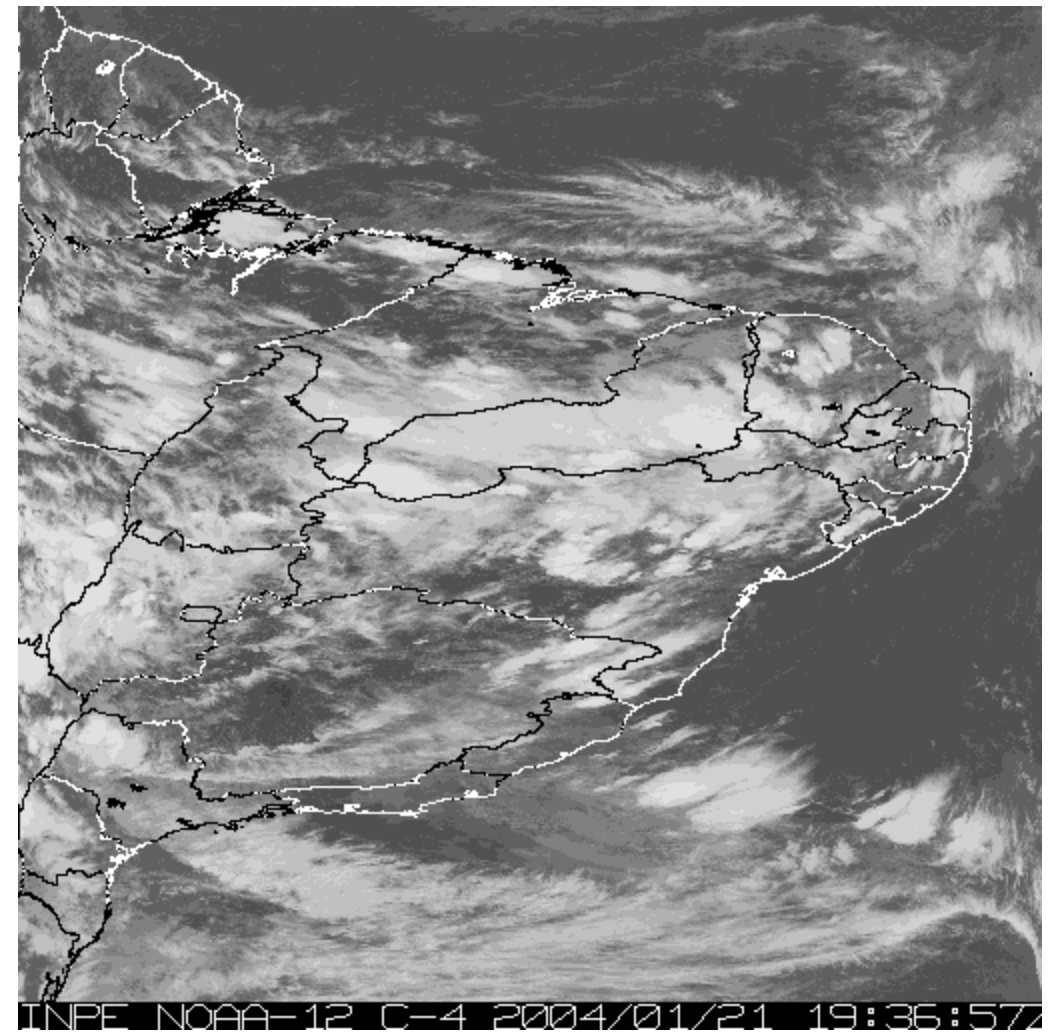

Figura 9 - Imagem do satélite NOAA do dia 21/01/2004. Fonte: CPTEC/INPE. 
De acordo com o AVADAN, os espaços urbano e rural foram afetados pelo evento durante as chuvas ocorridas no mês de janeiro, com registros acima do observado nos 13 anos anteriores ao evento. Os impactos mais frequentes foram "transbordamento e arrombamento de açudes, barreiros, canais, bem como, causando danos em habitações, estradas etc.”. O Quadro 3 mostra os danos materiais:

\begin{tabular}{|c|cc|c|c|c|}
\hline \multirow{2}{*}{ Danos Materiais } & \multicolumn{2}{|c|}{ Danificadas } & \multicolumn{2}{c|}{ Destruídas } & \multirow{2}{*}{ Total } \\
\hline Residências Populares & - & - & 108 & 756 & 756 \\
\hline Obras de Arte & 2 & 25 & - & - & 25 \\
\hline Estradas (km) & 30 & 30 & - & - & 30 \\
\hline Pav. de vias urbanas (mil m²) & 0,6 & 12 & - & - & 12 \\
\hline
\end{tabular}

Quadro 3 - Danos materiais quantificados em Caldas Brandão no reconhecimento de Estado de Emergência de 28/01/2014. Fonte: BRASIL, 2004. Elaboração: Gabriel de Paiva Cavalcante, 2017.

Ao todo, os prejuízos somam $\mathrm{R} \$ 823.000,00$, um quantitativo relevante para um município de receita reduzida (3,34 milhões de reais). Em termos percentuais, os prejuízos significam 24,6\% de toda a receita municipal, o que dá ao desastre natural uma proporção grande de destruição. $\mathrm{O}$ principal dano material foi a destruição de casas populares: 108 unidades habitacionais destruídas, somando um prejuízo de 756 mil reais.

$\mathrm{Na}$ Avaliação Conclusiva sobre a Intensidade do Desastre (Ponderação), a Defesa Civil classificou os danos humanos na categoria Médio ou Significativo, e os danos materiais como Importantes; o vulto dos prejuízos econômicos se enquadrara na categoria Importante, enquanto que os sociais, Médio ou Significativo; a necessidade dos recursos, por sua vez, foi classificada como Muito Vultuosa, porém, sem disponibilidade no SINDEC (BRASIL, 2004).

No que diz respeito aos Critérios Agravantes, o foco foi na preocupação com os desastres secundários (classificado como importante), já que o padrão evolutivo do desastre foi súbito e imprevisível e apresentou tendência ao agravamento. Como o desastre, em conclusão, foi classificado como de grande porte, a chuva de 126,6 mm do dia 01/02/2004 pode ter deflagrado mais impactos ou agravado os já existentes, porém sem registros no SINDEC.

\section{CONSIDERAÇÕES FINAIS}

Este trabalho analisou o regime histórico de chuvas entre 1990 e 2016 e os desastres naturais deflagrados no município de Caldas Brandão, Agreste da Paraíba. A eleição dos "anos-padrão" foi essencial para detalhar tal regime, o que possibilita a abordagem dinâmica dos elementos climáticos 
em detrimento da circulação atmosférica regional, fatores não contemplados quando se utiliza apenas a média histórica dos elementos climáticos.

Foram registrados 34 eventos de chuva intensa, ou seja, acima dos 60,0/dia mm. Os três eventos pluviométricos extremos (chuvas acima de 100,0 mm/dia) registrados ocorreram em anos chuvosos. O evento mais significativo, que ocorreu no dia 01/02/2004, registrou 126,6 mm, maior acumulado diário da série. Porém, o único desastre hidrometeorológico registrado pela Defesa Civil na área de estudo ocorreu após um episódio que acumulou 134,8 $\mathrm{mm}$ de chuvas em quatro dias, no qual o maior acumulado diário ocorreu na ordem de 85,8 mm (21/01/2004). Tal episódio gerou um decreto de Situação de Emergência. Os prejuízos, que somaram um montante financeiro de 823 mil reais, significaram grande parcela da receita municipal da época: $24,6 \%$.

Embora este estudo retrate um desastre natural de ocorrência local, abordando um município como território de análise, o estudo dos elementos climáticos e suas variações é válido para pesquisas de áreas próximas, que utilizem a região como área de estudo. Além disso, a relevância dos resultados sobre os tipos de tempo e a gênese dos mesmos sobressalta para o entendimento de problemas geográficos regionais.

A divulgação dos dados do desastre deflagrado pode auxiliar na gestão de eventos subsequentes, já que foi observado que os eventos de chuva intensa e extrema são frequentes no município estudado, servindo como ferramenta para o setor público planejar ações de prevenção, se preparar para o enfrentamento das consequências dos danos e impactos causados, além do gerenciamento das ações de resiliência e de reparação dos danos das famílias, especialmente no que tange às habitações destruídas, o que altera o tecido urbano das comunidades, gerando novas discussões que podem ser observadas por outros trabalhos.

\section{REFERÊNCIAS}

AESA. Agência Executiva de Gestão das Águas do Estado da Paraíba. Meteorologia - Chuvas. Disponível em: <http://www.aesa.pb.gov.br/aesa-website/meteorologia-chuvas/>. Acesso em: 24/05/2017.

AESA. Agência Executiva de Gestão das Águas do Estado da Paraíba. Geo-Portal AESA. Disponível em: <http://geoserver.aesa.pb.gov.br/geoprocessamento/geoportal>. Acesso em: 24/05/2017.

BRASIL. Sistema Nacional de Defesa Civil - SINDEC. Avaliação de Danos - AVADAN. Disponível em: <https://s2id-search.labtrans.ufsc.br/>. Acesso em: 25/05/2017.

BRASIL. Ministério da Integração Nacional. Instrução Normativa no 01, de 24 de Agosto de 2012 do Ministério da Integração Nacional, 2012. Disponível em: <http://www.mi.gov.br/documents/10157/3776390/Instru_Normativa_01.pdf/8634a6e3-78cc-422aaa1d-7312ce7f1055>. Acesso em: 25/05/2017. 
CASTRO, A. L. C. Glossário de defesa civil: estudo de riscos e medicina de desastres. Brasília: MPO/ Departamento de Defesa Civil, 1998. 283 p.

CAVALCANTI, A. S. Avaliação de padrões atmosféricos associados à ocorrência de chuvas extremas no litoral da região Nordeste do Brasil: aspectos numéricos na previsão operacional do tempo. Tese (Doutorado em Engenharia Mecânica) - Programa de Pós-Graduação em Engenharia Mecânica, Universidade Federal do Rio de Janeiro, Rio de Janeiro, 2009.

CLIMANÁLISE. Boletim de Monitoramento e Análise Climática. Cachoeira Paulista-SP, volume 19, número 01, janeiro/2004. Disponível em: <http://www6.cptec.inpe.br/revclima/boletim/>. Acesso em: 21/06/2017.

CLIMANÁLISE. Boletim de Monitoramento e Análise Climática. Cachoeira Paulista-SP, volume 19, número 02, fevereiro/2004. Disponível em: <http://www.cptec.inpe.br/products/climanalise>. Acesso em: 21/06/2017.

GONÇALVES, N. M. S. Impactos pluviais e desorganização do espaço urbano em Salvador. In: MONTEIRO, C. A. F.; MENDONÇA, F. (Orgs.). Clima urbano. São Paulo: Contexto, 2003. p. 69-91.

IBGE. Instituto Brasileiro de Geografia e Estatística. IBGE Cidades: Caldas Brandão. Disponível em: <https://cidades.ibge.gov.br/brasil/pb/caldas-brandao/panorama>. Acesso em: 05/11/2017.

MONTEIRO, C. A. F. Teoria e Clima Urbano. Série Teses e Monografias, $\mathrm{n}^{\circ}$ 25. São Paulo: Instituto de Geografia/USP, 1976.

MOURA, M. O.; PEREIRA, M. D. B. Dinâmica Atmosférica e as chuvas na cidade de João Pessoa. In: SIlvA, A. B.; GUTIERRES, H. E. P. GALVÃO, J. C. (Orgs.) Paraíba: Pluralidades e representações geográficas. Campina Grande: EDUFCG, 2015.

MOURA, M. O.; CUNICO, C. TEMOTEO, K. K. S. SILVA, N. T. Desastre Natural associado à ocorrência de chuva extrema na cidade de Patos, Paraíba. In: SILVA, A. B.; GUTIERRES, H. E. P. GALVÃO, J. C. (Orgs.) Paraíba 2: Pluralidades e representações geográficas. Campina Grande: EDUFCG, 2017.

OLÍMPIO, J. L. S. Desastres naturais associados à dinâmica climática no Estado do Ceará: subsídios à gestão dos riscos de secas e inundações. Dissertação. (Mestrado em Geografia). Fortaleza: Programa de Pós- graduação em Geografia/UFCE, 2013.

ROCHA, A. B. Proposta metodológica de gestão dos espaços-riscos de inundações urbanas em Mossoró/RN. Tese (Doutorado em Geografia) - Programa de Pós-Graduação em Geografia, Universidade Federal do Ceará, Fortaleza, 2015.

SANT'ANNA NETO, J. L. Ritmo Climático e a gênese das chuvas na Zona Costeira Paulista. (Dissertação de Mestrado). São Paulo: FFLCH/USP - Programa de Pós-Graduação em Geografia Física, 1990.

SILVA, R. N.; ARAÚJO, S. M. S. Desastres, riscos e vulnerabilidades em áreas urbanas: contribuições da geografia no período de 2000 a 2015. In: ALMEIDA, L. Q.; BINDÉ, P. J.; CARVALHO, R. J. M.; ARAÚJO, S. M. S. (Orgs.) Enfoques Multidisciplinares sobre Desastres. Natal/RN: SABEH, 2017. 
SILVA, N. T. Precipitações diárias intensas na cidade de João Pessoa, Paraíba. Monografia (Bacharelado em Geografia) - Departamento de Geociências, Universidade Federal da Paraíba, João Pessoa, 2014.

TEMOTEO, K. K. S. Eventos de chuvas intensas e extremas e seus impactos no espaço urbano de Campina Grande, Paraíba. Monografia (Bacharelado em Geografia) - Departamento de Geociências, Universidade Federal da Paraíba, João Pessoa, 2016.

TOMINAGA, L. K.; SANTORO, J.; AMARAL, R. Desastres naturais: conhecer para prevenir. São Paulo: Instituto Geológico, 2009.

ZAMPARONI, C. A. G. Áreas de risco, mobilidade urbana, vulnerabilidade e o poder público em Cuiabá/MT: Porque a população continua vivendo nas áreas de risco do córrego do barbado? Revista Brasileira de Climatologia, Mato Grosso, ano 10- vol.14, jan/jul. 2014.

ZANELLA, M. E. Inundações em Curitiba: impactos, risco e vulnerabilidade socioambiental. 2. ed. Fortaleza: Editora da UFC, 2014.

ZANELLA, M. E.; SALES, M. C. L.; ABREU, N. J. A. Análise das precipitações diárias intensas e impactos gerados em Fortaleza-CE. GEOUSP - Espaço e Tempo, n. 25, p; 53-68, 2009.

Recebido em: 17/12/2017

Aceito para publicação em: 